\title{
FLORÍSTICA E DIVERSIDADE DAS ESPÉCIES ARBUSTIVO-ARBÓREAS REGENERADAS NO SUB-BOSQUE DE Anadenanthera peregrina (L.) Speg.
}

\author{
Priscila Bezerra de Souza ${ }^{1}$, Agostinho Lopes de Souza ${ }^{2}$, Walter da Silva Costa ${ }^{3}$, \\ Ricardo Vieira Del Peloso ${ }^{4}$, Jacinto Moreira de Lana ${ }^{5}$
}

(recebido: 20 de outubro de 2010; aceito: 28 de fevereiro de 2012)

\begin{abstract}
RESUMO: Neste trabalho, objetivou-se analisar a composição florística e a estrutura da vegetação arbustivo-arbórea em plantio de Anadenanthera peregrina (L) Speg., no município de Naque, MG, de, aproximadamente, 10 ha, de propriedade da empresa Celulose Nipo - Brasileira SA, (19 $15^{\prime} 05^{\prime}$ 'S e $\left.42^{\circ} 20^{\prime} 30^{\prime} \mathrm{W}\right)$. Foram estabelecidas dez parcelas aleatórias de 20 x $50 \mathrm{~m}$ para amostrar os indivíduos com CAP igual ou maior que $15 \mathrm{~cm}$ (Classe I). No centro de cada parcela de $20 \mathrm{x} 50 \mathrm{~m}$, foi instalada uma sub-parcela de $10 \times 10 \mathrm{~m}$ para amostrar os indivíduos com altura total igual ou maior que $1,30 \mathrm{~m}$ do solo até CAP menor que $15 \mathrm{~cm}$ (Classe II). Os indivíduos das parcelas de 20 x $50 \mathrm{~m}$ foram classificados quanto às síndromes de dispersão e categorias sucessionais. Além disso, foram realizadas a distribuição diamétrica dos indivíduos amostrados. Foram encontrados 510 indivíduos na classe I, pertencentes a 10 famílias, 15 gêneros e 15 espécies e na classe II, 47 indivíduos de 10 famílias, 14 gêneros e 14 espécies, com índice de similaridade de Sorensen igual a 48\%. A classificação sucessional das espécies amostradas nas classes I e II revelou maior riqueza de espécies iniciais na sucessão secundária, com o grupo formado pelas secundárias iniciais e pioneiras, totalizando $93,5 \%$ na classe I e $93 \%$ na classe II. Considerando as síndromes de dispersão, classe I 60\% das espécies possuem dispersão anemocórica. Quanto à distribuição diamétrica por classe de diâmetro de Anadenanthera peregrina e das demais espécies, respectivamente, distribuíram-se em "J"-invertido.
\end{abstract}

Palavras-chave: Síndromes de dispersão, classificação sucessional, estrutura diamétrica.

\section{FLORISTIC AND DIVERSITY OF TREE SPECIES AND SHRUB UNDER A STAND OF Anadenanthera peregrina (L.) Speg.}

\begin{abstract}
The aim of this study was to analyze the floristic composition and structure of tree-shrub vegetation under a stand of Anadenanthera peregrina, in the municipality of Naque, Minas Gerais State, Brazil. The study was conducted in an area of

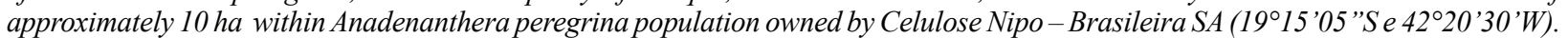
Ten random plots $(20 \times 50 \mathrm{~m}$ ) were established to sample individuals with $\mathrm{CBH}$ (diameter at breast height) $\geq 15 \mathrm{~cm}$ (Class I). It was installed a subplot of $10 \times 10 \mathrm{~m}$ in the center of each plot to sample individuals with total height $\geq t 1.30 \mathrm{~m}$ above the ground and $\mathrm{CBH}<15 \mathrm{~cm}$ (Class II). Individuals in $20 \times 50 \mathrm{~m}$ plots were classified according to their dispersal syndromes and successional guilds. In addition, it was performed the diameter distribution of samples. 510 individuals were found in Class I, belonging to 10 botanical families, 15 genera and 15 species; in Class II, 47 individuals from 10 families, 14 genera and 14 species, with the Sorensen similarity index equal to 48\%. Classification of successional species sampled in classes I and II showed higher species richness in early secondary succession, with the group formed by pioneers and early secondary totaling 93.5\% in Class I and 93\% in Class II. Regarding dispersal syndromes, $60 \%$ of species in Class I are wind-dispersed. Diameter distribution by diameter class of Anadenanthera peregrina and other species were classified into reverse J-shaped distribution.
\end{abstract}

Key words: Dispersal syndrome, successional classification, diameter structure.

\section{INTRODUÇÃO}

A conservação e recuperação de áreas de reserva legal e de preservação permanente nas propriedades rurais são primordiais para a gestão das propriedades e para a sustentabilidade (WISCH; MELO, 2005).
No que diz respeito à legislação de áreas protegidas, o Código Florestal (BRASIL, 1965), postula que essas devem permanecer com cobertura vegetal natural e, naquelas áreas onde a vegetação foi suprimida, a recuperação e a restauração devem ser realizadas por meio de plantio e, ou, regeneração natural de espécies nativas.

${ }^{1}$ Bióloga, Professora Doutora em Botânica - Universidade Federal do Tocantins - Departamento de Engenharia Florestal - 77402-970 - Gurupi, TO, Brasil - pri_ufv@yahoo.com.br

${ }^{2}$ Engenheiro Florestal, Professor Doutor em Engenharia Florestal - Universidade Federal de Viçosa - Departamento de Engenharia Florestal 36570-000 - Viçosa, MG, Brasil - alsouza@ufv.br

${ }^{3}$ Engenheiro Florestal, Consultor Ambiental - Celulose Nipo-Brasileira AS/CENIBRA - Departamento de Meio Ambiente e Qualidade - Ipatinga, MG, Brasil - walterfloresteiro@hotmail.com

${ }^{4}$ Engenheiro Florestal, Mestrando em Ciência Florestal - Universidade Federal de Viçosa - Departamento de Engenharia Florestal - 36570-000 Viçosa, MG, Brasil - ricardopeloso@gmail.com

${ }^{5}$ Engenheiro Florestal, Mestre em Botânica - Celulose Nipo-Brasileira AS/CENIBRA - Departamento de Meio Ambiente e Qualidade - Ipatinga, MG, Brasil - jacinto.lana@cenibra.com.br

Cerne, Lavras, v. 18, n. 3, p. 413-421, jul./set. 2012 
As áreas protegidas, principalmente as áreas de reserva legal, além de conservar a biodiversidade, podem fornecer produtos florestais madeireiros e não-madeireiros, com destaque para os serviços ambientais como o sequestro de $\mathrm{CO}_{2}$ (MINAS GERAIS, 2010; VILAR et al., 2009).

Diversos estudos têm mostrado que plantações homogêneas de espécies florestais nativas e exóticas podem acelerar o processo de sucessão florestal em áreas degradadas, catalisando plantas nativas em seus subbosques (GELDENHUYS, 1997; NAPPO et al., 2000).

Anadenanthera peregrina (L.) Speg., conhecida popularmente como angico-vermelho, é uma espécie arbórea nativa do Brasil da subfamília Mimosoideae que apresenta elevado potencial para produtos florestais madeireiros e não-madeireiros, além de apresentar regeneração natural e de formar povoamentos naturais monodominantes. A espécie Anadenanthera peregrina ocorre indiferentemente em solos secos e úmidos; é tolerante a solos rasos, compactados, mal drenados e até encharcados, de textura média a argilosa. Apresenta crescimento de moderado a rápido, podendo atingir, quando em ótimas condições ecológicas, produtividades de até 25,00 $\mathrm{m}^{3} \cdot$ ha $^{-1}$.ano-1 (CARVALHO, 2003).

$\mathrm{Na}$ pesquisa, objetivou-se analisar a composição florística e a estrutura da vegetação arbustivo-arbórea em plantio de Anadenanthera peregrina, com idade de aproximadamente 30 anos, no município de Naque, MG, com o propósito de conhecer as principais espécies que cohabitam esse plantio de recuperação, a tendência da distribuição dos diâmetros e a contribuição da regeneração natural na diversidade de espécies. A hipótese central é: uma dominância forte e prováveis efeitos alelopáticos contribuem para a baixa diversidade de espécies arbustivoarbóreas (ODUM, 1983), sobretudo em plantios equiâneos puros para fins de restauração florestal.

\section{MATERIAL E MÉTODOS}

O estudo foi desenvolvido num povoamento de Anadenanthera peregrina de aproximadamente 10 ha, de propriedade da empresa Celulose Nipo - Brasileira SA -

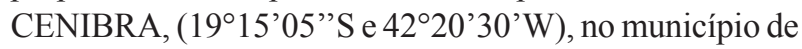
Naque, MG. Esse povoamento foi implantado na década de 1980, no espaçamento inicial de 3,0 x 2,0 m, e encontra-se nas proximidades de talhões de Eucalyptus sp.

A área de estudo pertence à região fitoecológica da Floresta Estacional Semidecidual Submontana (VELOSO et al., 1991) e está inserida na região bioclimática 5, com altitude que varia de 200 a 900 m (a altitude local é de $300 \mathrm{~m}$ ), temperatura média anual que varia de 20 a $23^{\circ} \mathrm{C} \mathrm{e}$ precipitação média anual que oscila entre 1100 e $1400 \mathrm{~m}$ (GOLFARI, 1975).

A vegetação na área do trabalho foi avaliada em outubro de 2009, utilizando-se o método de parcelas (MUELLER-DOMBOIS; ELLENBERG, 1974). Foram estabelecidas dez parcelas aleatórias de 20 x $50 \mathrm{~m}$ para amostrar os indivíduos com CAP igual ou maior que $15 \mathrm{~cm}$ (Classe I). No centro de cada parcela de 20 x $50 \mathrm{~m}$, foi instalada uma subparcela de $10 \times 10 \mathrm{~m}$ para amostrar os indivíduos com altura total igual ou maior que $1,30 \mathrm{~m}$ do solo e CAP menor que $15 \mathrm{~cm}$ (Classe II).

Nas parcelas de 20 x 50 m, os indivíduos arbustivos - arbóreos da classe I foram medidos, identificados e classificados quanto às síndromes de dispersão zoocorica e não-zoocorica e quanto às categorias sucessionais: espécies pioneiras, secundárias iniciais, secundárias tardias e sem classificação, sendo os grupos relacionados às categorias de sucessão: fase inicial, média e avançada de sucessão que seguiu a proposta de Lopes et al. (2002), Paula et al. (2004), Ribas et al. (2003) e Silva et al. (2003). A identificação taxonômica foi realizada por meio de comparações com material do Herbário VIC da Universidade Federal de Viçosa, literatura especializada e consultas a especialistas, quando necessário. Após a identificação, o material fértil coletado foi depositado no Herbário VIC da UFV. Para a atualização dos binômios específicos foi utilizado o site do Missouri Botanical Garden (http://www.mobot. org/W3T/search/vast.html), no mês de junho de 2010. O sistema de classificação adotado foi APG II (SOUZA; LORENZI, 2005).

Para a análise da estrutura horizontal da classe I, foram utilizados os parâmetros fitossociológicos de densidade, dominância, frequência, valor de cobertura e importância, bem como o volume total e comercial. Na classe II, foram utilizados apenas os parâmetros fitossociológicos de densidade, dominância e frequência. Os dados de campo das classes I e II foram processados no programa Mata Nativa 2 (CONSULTORIA E DESENVOLVIMENTO DE SISTEMAS - CIENTEC, 2006) e interpretados de acordo com (MUELLERDOMBOIS; ELLEMBERG, 1974; PIELOU, 1975). O volume total com casca das árvores individuais (Vtcc) foi estimado pela seguinte equação ajustada para floresta secundária (CETEC, 1995):

Vtcc $=0,000074230_{*} \mathrm{DAP}^{1,707348}{ }_{*} \mathrm{HT}^{1,16873}, \mathrm{com} \mathrm{R}^{2}=93,30 \%$.

Cerne, Lavras, v. 18, n. 3, p. 413-421, jul./set. 2012 
Já, o volume comercial com casca (Vcc) foi estimado pela seguinte equação (SOARES et al., 2010):

$\mathrm{Vcc}=0,000109$ DAP $^{2,134416}{ }_{*} \mathrm{HF}^{0,568317}, \operatorname{com~R}^{2}=97,98 \%$

em que DAP $=$ diâmetro de tronco medido em $\mathrm{cm}$ a $1,30 \mathrm{~m}$ do solo, $\mathrm{HT}$ = altura total estimada em $\mathrm{m}$ e HF = altura do fuste estimada em $\mathrm{m}$.

A distribuição diamétrica foi obtida mediante o cômputo dos indivíduos amostrados de cada espécie dentro da classe diamétrica a que pertencessem (HARPER, 1977). As classes de diâmetro foram estabelecidas com amplitude de $5 \mathrm{~cm}$, a partir do diâmetro mínimo de $3,18 \mathrm{~cm}$. Para a obtenção das tabelas de distribuição diamétrica foi utilizado o programa Mata Nativa 2 (CIENTEC, 2006).

\section{RESULTADOS E DISCUSSÃO}

\subsection{Florística e estrutura horizontal}

Na Tabela 1, encontra-se a relação das espécies arbustivo - arbóreas das classes I e II amostradas no povoamento de Anadenanthera peregrina (L.) Speg. As espécies foram listadas em ordem alfabética de família botânica, nomes genéricos e específicos, junto com sua classificação quanto ao grupo ecológico e tipo de síndrome de dispersão de diásporos.

Tabela 1 - Lista das espécies arbustivo-arbóreas das classes I e II amostradas no plantio de Anadenanthera peregrina, município de Naque, MG, em ordem alfabética de famílias, subfamílias e espécies, com as respectivas categorias sucessionais (CS), pioneira (P), secundária inicial (SI) e secundária tardia (ST); e síndromes de dispersão (SD), zoocórica (Zoo) e anemocórica (Ane).

Table 1 - List of tree-shrub species of Class I and II sampled under a stand of Anadenanthera peregrina in Naque, Minas Gerais State, in alphabetical order of families, subfamilies and species, with their respective guilds (CS), pioneer $(P)$, early secondary (SI) and secondary delayed (ST) and dispersal syndrome (SD), zoochoric (Zoo) and anemocoric (ANE).

\begin{tabular}{|c|c|c|c|}
\hline \multirow{2}{*}{ Famílias/Subfamílias/Espécies } & \multicolumn{2}{|c|}{ Classes } & \multirow{2}{*}{ CS SD } \\
\hline & $\mathrm{I}$ & II & \\
\hline \multicolumn{4}{|l|}{ Annonaceae } \\
\hline Annona cacans Warm. & $\mathrm{x}$ & & SI Zoo \\
\hline \multicolumn{4}{|l|}{ Apocynaceae } \\
\hline Aspidosperma parvifolium A. DC. & & $\mathrm{X}$ & ST Ane \\
\hline
\end{tabular}

Tabela 1 - Continuação...

Table 1 - Continued...

\begin{tabular}{lrrrr}
\hline \multirow{2}{*}{ Famílias/Subfamílias/Espécies } & \multicolumn{2}{c}{ Classes } & & \\
\cline { 2 - 3 } & I & II & \\
\hline $\begin{array}{l}\text { Aspidosperma subincanum Mart. ex A. } \\
\text { DC. }\end{array}$ & & & ST Ane \\
Peschiera affinis (Müll. Arg.) Miers & x & X & SI Zoo \\
Asteraceae & & & & \\
Asteraceae sp. & X & PI Ane \\
Gochnatia sp. & X & PI Ane \\
Vernonia sp. & X & PI Zoo
\end{tabular}

Bignoniaceae

Cybistax antisyphilitica (Mart.) Mart.

Sparattosperma leucanthum (Vell.) K. Schum.

$\mathrm{x}$

$x \quad X$ SI Ane

Cannabaceae

Celtis iguanaea (Jacq.) Sarg.

X PI Zoo

Fabaceae Caesalpinioideae

Apuleia leiocarpa (Vogel) J.F. Macbr. $\quad$ x $\quad$ SI Ane

Caesalpinia echinata Lam.

$x \quad$ SI Ane

Fabaceae Mimosoideae

Anadenanthera peregrina (L.) Speg. $\quad$ X X SI Ane

Fabaceae Papilionoideae

Dalbergia nigra (Vell.) Allemao ex Benth.

Platypodium elegans Vogel

$x \quad$ SI Ane

Melastomataceae

$x \quad X$ SI Ane

Miconia sp.

x PI Zoo

Moraceae

Brosimum guianense (Aubl.) Huber

x PI Zoo

Myrtaceae

Myrcia sp.

$\mathrm{X}$ SI Zoo

Nyctaginaceae

Guapira ferruginea (Klotzsch ex Choisy)

Lundell

X SI Zoo

Salicaceae

$\begin{array}{lllll}\text { Casearia decandra Jacq. } & \text { X } & \text { X } & \text { SI Ane }\end{array}$

Sapindaceae

$\begin{array}{lllll}\text { Diatenopteryx sorbifolia Radlk. } & \text { X } & \text { X } & \text { SI } & \text { Zoo }\end{array}$

Solanaceae

Solanum sp.

x X PI Zoo

Cerne, Lavras, v. 18, n. 3, p. 413-421, jul./set. 2012 
$\mathrm{Na}$ classe I, foram amostrados 510 indivíduos arbustivos - arbóreos, pertencentes a 10 famílias, 15 gêneros e 15 espécies e na classe II, 47 indivíduos de 10 famílias botânicas, 14 gêneros e 14 espécies, com índice de similaridade igual a $48 \%$ (Tabela 1). Essa riqueza de espécies é inferior à encontrada em outro estudo realizado em um povoamento de Anadenanthera peregrina, que foi de 66 espécies em Lavras - MG (NASCIMENTO et al., 2009). A discrepância de riqueza entre as duas áreas estudadas pode ser atribuída, em parte, aos diferentes critérios de inclusão e de amostragem. Nota-se, também, que estudos realizados em florestas tropicais sugerem que tanto o estágio sucessional quanto o histórico de perturbação podem influenciar o número de espécies encontradas em uma comunidade (WERNECK et al., 2000).

Comparativamente a outros estudos da vegetação arbustiva - arbórea realizados em sub-bosque de Eucalyptus, nota-se que a riqueza variou de local para local: 25 espécies em Assis, SP (DURIGAN et al., 1997), 47 em Paraopeba, MG (NERI et al., 2005) e 50 espécies em Viçosa, MG (SOUZA et al., 2007).

A classificação sucessional das espécies amostradas nas classes I e II (Tabela 1) revelou maior riqueza de espécies iniciais na sucessão secundária, com o grupo formado pelas secundárias iniciais e pioneiras, totalizando 93,5\% na classe I e 93\% na classe II. Quanto ao número de indivíduos, as espécies secundárias tardias somaram $6,5 \%$ na classe I e $7 \%$ classe II. Esses resultados indicaram que o povoamento de Anadenanthera peregrina forneceu condições ecológicas razoáveis para a catalisação de espécies dos diferentes grupos ecológicos.

A dominância forte combinada com intensos efeitos alelopáticos de uma espécie inibe o crescimento e/ou desenvolvimento da regeneração natural de espécies arbustivo-arbóreas (ODUM, 1983). Vale ressaltar que Anadenanthera peregrina, apesar de ser espécie decídua, decorrente do seu elevado potencial de crescimento em plantio equiâneo monoespécífico, aliado a efeitos alelopáticos, domina a comunidade, forma dossel homogêneo e fechado, com pouca luminosidade no período de desenvolvimento vegetativo, o que, consequentemente, dificulta a germinação, a sobrevivência, o crescimento e o desenvolvimento da regeneração natural de espécies arbustivo-arbóreas autóctones. As citadas propriedades alelopáticas de $A$. peregrina, com a sua alta concentração de tanino nos frutos e na casca do tronco, bem como alcalóide bufotenina em sementes e partes vegetativas, têm mostrado efeito seletivo sobre o banco de sementes e a regeneração (NASCIMENTO et al., 2009).

Cerne, Lavras, v. 18, n. 3, p. 413-421, jul./set. 2012
Considerando as síndromes de dispersão de sementes, classe I 60\% (9) das espécies amostradas possuem dispersão anemocórica (Tabela 1). Esse fato pode ser explicado pela distância de fontes de propágulos, uma vez que, o plantio de $A$. peregrina fica próximo a plantios de Eucalyptus sp., dificultando, assim, a regeneração florestal no sub-bosque dessa floresta (RODRIGUES et al., 2004). Entretanto, considerando as síndromes de dispersão de sementes, da classe II, $50 \%$ (7) das espécies amostradas possuem dispersão zoocórica e os outros 50\% (7) espécies dispersão anemocórica (Tabela 1). Dada a importância da zoocoria para a dispersão de sementes de espécies arbustivo-arbóreas, a proximidade de fontes dessas sementes é fator primordial para a regeneração florestal no sub-bosque de florestas plantadas. Povoamentos florestais homogêneos localizados próximos a fragmentos florestais tendem a ter mais rápida colonização do sub-bosque, bem como maior número de espécies do que plantios isolados dentro de grandes paisagens degradadas (LOUMETO; HUTTEL, 1997).

Os índices de diversidades de Shannon (H') e equabilidade (J') foram, respectivamente: 0,53 e 0,20 , para a classe I (CAP $\geq 5,0 \mathrm{~cm} ; 2,33$ e 0,88 , para a classe II (HT $\geq 1,30 \mathrm{~m}$ do solo até $\mathrm{CAP}<5,0 \mathrm{~cm}$ ); e 1,74 e 0,55, para a população total (HT $\geq 1,30 \mathrm{~m}$ do solo). Então, apesar da dominância forte de Anadenanthera peregrina aliada a efeitos alelopáticos, a regeneração natural de espécies arbustivo-arbóreas contribuiu para aumentar a diversidade de espécies arbustivo-arbóreas autóctones no plantio equiâneo monoespecífico. Em levantamentos realizados especificamente com vegetação remanescente de sub-bosque na região do Rio Doce, $\mathrm{MG}$, os valores de H' têm sido bastante variáveis, refletindo o estádio sucessional dessas florestas (SOUZA et al., 2008). Já o índice de diversidade (H') para a classe II foi de 2,33 e a equabilidade (J') de 0,88 . Em levantamento realizado em sub-bosque de Eucalyptus grandis em Viçosa, MG (SOUZA et al., 2007), o índice de diversidade (H') foi de 2,89 e a eqüabilidade (J') de 0,74 . Nessa mesma reserva, foram obtidos valores de H' de 1,91 para o sub-bosque de um trecho de floresta secundária inicial e de 3,15 para trecho de floresta madura sem intervenção antrópica nos últimos 40 anos (SILVA JUNIOR et al., 2004). No subbosque de povoamento homogêneo de Mimosa scabrella Benth., em Poços de Caldas, MG, foi estimado valor de diversidade de 2,85 (NAPPO et al., 2000), enquanto no sub-bosque de povoamento de Eucalyptus saligna em Itatinga, SP, foram estimados valores de 2,51 e 3,75 (SARTORI et al., 2002). Portanto, pode-se considerar 
que a diversidade do povoamento de Anadenanthera peregrina, avaliada na classe II, indica condição similar a do sub-bosque de florestas estacionais semideciduais secundárias da região e do sub-bosque de povoamentos de florestas plantadas em outras localidades do Sudeste brasileiro.

As famílias mais ricas na classe I foram Fabaceae com cinco espécies, seguida por Apocynaceae (3), Bignoniaceae e Asteraceae (2), sendo que as demais famílias apresentaram uma espécie cada (Tabela 1). $\mathrm{O}$ destaque de Fabaceae em riqueza de espécies já era esperado, uma vez que essa família é característica de florestas semidecíduas e tem se destacado na maioria dos levantamentos realizados em formações florestais (ARAÚJO et al., 2005; SILVA et al., 2003). Além disso, a alta densidade das fabáceas pode ser atribuída à capacidade de fixação biológica de nitrogênio de muitas espécies dessa família, facilitando a regeneração em solos pobres e degradados (CAMPELLO, 1998).
As espécies que apresentaram maiores valores de importância (VI) foram também as que apresentaram maiores valores de cobertura (Tabela 2), sendo elas: Anadenanthera peregrina (72,71\%), Platypodium elegans $(5,15 \%)$, Sparattosperma leucanthum $(5,03)$, Brosimum guianense $(2,85)$ e Diatenopteryx sorbifolia $(1,58)$.

Já, as famílias mais ricas na classe II (Tabela 3) foram Asteraceae, com três espécies, seguidas por Fabaceae e Apocynaceae com duas respectivamente, as demais famílias apresentaram apenas uma espécie. Para a flora fanerogâmica do Bioma Cerrado (MENDONÇA et al., 1998) apontaram Fabaceae, Asteraceae e Poaceae como sendo as famílias mais ricas.

Dados similares aos encontrados foram citados para altitudes entre 650 e $1900 \mathrm{~m}$ nos estados de Minas Gerais, Rio de Janeiro, São Paulo, Espírito Santo e Paraná (MIKICH; SILVA, 2001; OLIVEIRA-FILHO; FONTES, 2000; WERNECK et al., 2000) em Floresta Estacional Semidecidual e Floresta Ombrófila Densa.

Tabela 2 - Parâmetros fitossociológicos das espécies da classe I amostradas num povoamento de Anadenanthera peregrina, Naque MG, ordenadas de forma decrescente em valor de importância, em que: DA = densidade absoluta, $\mathrm{DR}=$ densidade relativa $(\%), \mathrm{FA}=$ frequência absoluta, $\mathrm{FR}=$ frequência relativa $(\%), \mathrm{DoA}=$ dominância absoluta $\left(\mathrm{m}^{2} / \mathrm{ha}\right)$, DoR = dominância relativa $(\%)$, VC = valor de cobertura (\%) e VI = valor de importância (\%).

Table 2 - Phytosociological parameters of Class I species sampled under a stand of Anadenanthera peregrina, Naque, Minas Gerais State, sorted in descending order of importance value, where: $D A=$ absolute density, relative density $=D R(\%), F A=$ absolute frequency, $F R=$ relative frequency $(\%)=$ absolute dominance DoA $\left(\mathrm{m}^{2} / \mathrm{ha}\right), \mathrm{DoA}=$ relative dominance $(\%)$, VC $=$ cover value $(\%)$ and $V I=$ importance value $(\%)$.

\begin{tabular}{lcccccccc}
\hline Nome científico & DA & DR & FA & FR & DoA & DoR & VC (\%) & VI (\%) \\
\hline Anadenanthera peregrina (L.) Speg. & 508,9 & 89,8 & 100,0 & 31,0 & 19,792 & 97,3 & 93,6 & 72,7 \\
Platypodium elegans Vogel & 24,4 & 4,3 & 33,3 & 10,3 & 0,166 & 0,8 & 2,6 & 5,2 \\
Solanum sp. & 1,1 & 0,2 & 11,1 & 3,5 & 0,004 & 0,0 & 0,1 & 1,2 \\
Sparattosperma leucanthum (Vell.) K. Schum. & 5,6 & 1,0 & 44,4 & 13,8 & 0,064 & 0,3 & 0,7 & 5,0 \\
Aspidosperma subincanum Mart. ex A. DC. & 1,1 & 0,2 & 11,1 & 3,5 & 0,003 & 0,0 & 0,1 & 1,2 \\
Miconia sp. & 6,7 & 1,2 & 11,1 & 3,5 & 0,016 & 0,1 & 0,6 & 1,6 \\
Annona cacans Warm. & 1,1 & 0,2 & 11,1 & 3,5 & 0,003 & 0,0 & 0,1 & 1,2 \\
Caesalpinia echinata Lam. & 1,1 & 0,2 & 11,1 & 3,5 & 0,009 & 0,0 & 0,1 & 1,2 \\
Brosimum guianense (Aubl.) Huber & 3,3 & 0,6 & 22,2 & 6,9 & 0,222 & 1,1 & 0,8 & 2,9 \\
Peschiera affinis (Müll. Arg.) Miers & 2,2 & 0,4 & 11,1 & 3,5 & 0,007 & 0,0 & 0,2 & 1,3 \\
Dalbergia nigra (Vell.) Allemao ex Benth. & 1,1 & 0,2 & 11,1 & 3,5 & 0,010 & 0,1 & 0,1 & 1,2 \\
Apuleia leiocarpa (Vogel) J.F. Macbr. & 1,1 & 0,2 & 11,1 & 3,5 & 0,010 & 0,1 & 0,1 & 1,2 \\
Diatenopteryx sorbifolia Radlk. & 6,7 & 1,2 & 11,1 & 3,5 & 0,026 & 0,1 & 0,7 & 1,6 \\
Cybistax antisyphilitica (Mart.) Mart. & 1,1 & 0,2 & 11,1 & 3,5 & 0,004 & 0,0 & 0,1 & 1,2 \\
Casearia decandra Jacq. & 1,1 & 0,2 & 11,1 & 3,5 & 0,003 & 0,0 & 0,1 & 1,2 \\
\hline Total & 566,7 & 100 & 322,2 & 100 & 20,339 & 100 & 100 & 100 \\
\hline
\end{tabular}

Cerne, Lavras, v. 18, n. 3, p. 413-421, jul./set. 2012 
Tabela 3 - Parâmetros fitossociológicos das espécies da classe II em um povoamento de Anadenanthera peregrina, Naque - MG, ordenadas de forma decrescente em valor de importância, em que DA = densidade absoluta, $\mathrm{DR}=$ densidade relativa $(\%), \mathrm{FA}=$ frequência absoluta, $\mathrm{FR}=$ frequência relativa (\%) e VI* = valor de importância (\%).

Table 3 - Phytossociological parameters p of Class II species under a stand of Anadenanthera peregrina, in Naque, Minas Gerais State, sorted in descending order of importance value. $D A=$ absolute density, relative density $=D R(\%)$, FA = absolute frequency, $F R=$ relative frequency $(\%)$ and $V I *=$ importance value $(\%)$.

\begin{tabular}{|c|c|c|c|c|c|}
\hline Nome científico & DA & DR & FA & FR & $\mathrm{VI}^{*}(\%)$ \\
\hline Anadenanthera peregrina (L.) Speg. & 133,3 & 25,5 & 66,7 & 21,4 & 23,5 \\
\hline Platypodium elegans Vogel & 11,1 & 2,1 & 11,1 & 3,6 & 2,9 \\
\hline Solanum sp. & 22,2 & 4,3 & 11,1 & 3,6 & 3,9 \\
\hline Sparattosperma leucanthum (Vell.) K. Schum. & 22,2 & 4,3 & 22,2 & 7,1 & 5,7 \\
\hline Peschiera affinis (Müll. Arg.) Miers & 11,1 & 2,1 & 11,1 & 3,6 & 2,9 \\
\hline Diatenopteryx sorbifolia Radlk. & 22,2 & 4,3 & 11,1 & 3,6 & 3,9 \\
\hline Casearia decandra Jacq. & 22,2 & 4,3 & 11,1 & 3,6 & 3,9 \\
\hline Aspidosperma parvifolium A. DC. & 22,2 & 4,3 & 11,1 & 3,6 & 3,9 \\
\hline Celtis iguanaea (Jacq.) Sarg. & 77,8 & 14,9 & 55,6 & 17,9 & 16,4 \\
\hline Vanillosmopsis sp. & 44,4 & 8,5 & 22,2 & 7,1 & 7,8 \\
\hline Myrcia sp. & 66,7 & 12,8 & 22,2 & 7,1 & 10,0 \\
\hline Guapira ferruginea (Klotzsch ex Choisy) Lundell & 22,2 & 4,3 & 11,1 & 3,6 & 3,9 \\
\hline Vernonia sp.1 & 11,1 & 2,1 & 11,1 & 3,6 & 2,9 \\
\hline Gochnatia sp.1 & 33,3 & 6,4 & 33,3 & 10,7 & 8,5 \\
\hline Total & 522,2 & 10 & 311,1 & 100 & 100 \\
\hline
\end{tabular}

Anadenanthera peregrina foi a espécie que apresentou maiores densidades (DA) e (DR), já Platypodium elegans e Sparattosperma leucanthum apresentaram maiores frequência (FA) e (FR) (Tabela 2).

\subsection{Estrutura paramétrica}

A estrutura paramétrica (Tabela 4) refere-se às distribuições dos parâmetros densidade absoluta $\left(n \cdot \mathrm{ha}^{-1}\right)$, dominância absoluta $\left(\mathrm{m}^{2} \cdot \mathrm{ha}^{-1}\right)$ e volume $\left(\mathrm{m}^{3} \cdot \mathrm{ha}^{-1}\right)$ por classe de diâmetro. Observa-se que os números de fustes por hectare (n.ha ${ }^{-1}$ ) e por classe de diâmetro de Anadenanthera peregrina, do povoamento com todas as espécies e das demais espécies, respectivamente, distribuíram-se, seguindo a tendência típica de florestas inequiâneas, ou seja, em “J”-invertido (LOETSCH et al., 1973).

O formato de "J"-invertido das estruturas diamétricas de Anadenanthera peregrina, do povoamento com todas as espécies e das demais espécies, ou seja, excluindo-se os fustes de Anadenanthera peregrina são ratificadas pelas seguintes equações exponenciais negativas ajustadas aos dados da Tabela 4 :

Cerne, Lavras, v. 18, n. 3, p. 413-421, jul./set. 2012
$D A_{j}=169,3798 e^{-0,0466 D j}, \operatorname{com~R}^{2}=94,6 \%$ e $\mathrm{S}_{\mathrm{y} \cdot \mathrm{x}}= \pm 15,49$ (Anadenanthera peregrina)

$D A_{j}=226,0322 e^{-0,0558 D j}$, com R $^{2}=98,4 \% \mathrm{e} \mathrm{S}_{\mathrm{y} . \mathrm{x}}= \pm 9,69$ (todas as espécies)

$D A_{j}=1177,333 e^{-0,441 D j}$, com $\mathrm{R}^{2}=99,8 \%$ e $\mathrm{S}_{\mathrm{y} \cdot \mathrm{x}}= \pm 1,48$ (demais espécies)

Do total de 1.089 fustes por hectare, Anadenanthera peregrina contribuiu com 508 (47\%) com DAP $\geq 5,0 \mathrm{~cm}$ (classe I) e $134(12 \%)$ na classe II (altura total igual ou maior que $1,30 \mathrm{~m}$ do solo até $\mathrm{CAP}$ menor que $15 \mathrm{~cm}$ ). As demais 22 espécies arbóreas e arbustivo-arbóreas somaram 447 (41\%) fustes por hectare, sendo 391 (36\%) na classe II. Todas as 23 espécies contribuíram com 525 (48\%) fustes por hectare na classe II. Num estudo de estrutura de sub-bosque herbáceo arbustivo (CAP $<10 \mathrm{~cm}$ até altura maior que $20 \mathrm{~cm}$ ), Meira Neto e Martins (2003) verificaram que o conjunto das espécies do sub-bosque do componente arbóreo apresentou curvas com forma de "J"-invertido. Esse formato de "J"-invertido, segundo os autores supracitados, deveu-se ao constante recrutamento e à taxa de mortalidade entre as classes. 
Tabela 4 - Estrutura paramétrica de Anadenanthera peregrina e das demais espécies amostradas nas classes I e II do plantio de angico, Naque, MG.

Table 4 - Parametric structure of Anadenanthera peregrina and other species sampled in Classes I and II of planting angico, Naque, $M G$.

\begin{tabular}{|c|c|c|c|c|c|c|c|c|c|c|c|c|c|c|}
\hline \multirow{2}{*}{ Espécie } & \multirow{2}{*}{ Par. } & \multicolumn{12}{|c|}{ Centro de classe de DAP em $\mathrm{cm}$} & \multirow{2}{*}{ Total } \\
\hline & & 2,5 & 7,5 & 12,5 & 17,5 & 22,5 & 27,5 & 32,5 & 37,5 & 42,5 & 47,5 & 52,5 & 57,5 & \\
\hline \multirow{4}{*}{ A. peregrina (L.) Speg. } & DA & 134,4 & 93,3 & 115,6 & 91,1 & 73,3 & 47,8 & 30,0 & 32,2 & 15,6 & 2,2 & 4,4 & 2,2 & 642,2 \\
\hline & DoA & 0,0 & 0,5 & 1,4 & 2,2 & 2,8 & 2,8 & 2,5 & 3,4 & 2,2 & 0,4 & 0,9 & 0,6 & 19,8 \\
\hline & VTcc & 0,0 & 2,1 & 7,7 & 15,7 & 24,9 & 26,8 & 25,9 & 35,2 & 25,2 & 2,9 & 9,8 & 8,4 & 184,6 \\
\hline & VFec & 0,0 & 1,8 & 7,1 & 13,9 & 22,4 & 24,9 & 22,4 & 29,3 & 20,6 & 3,2 & 7,5 & 7,6 & 160,8 \\
\hline \multirow{4}{*}{ Demais espécies (22) } & DA & 391,1 & 42,2 & 8,9 & 1,1 & 1,1 & 1,1 & 0,0 & 0,0 & 1,1 & 0,0 & 0,0 & 0,0 & 446,7 \\
\hline & DoA & 0,0 & 0,1 & 0,1 & 0,0 & 0,0 & 0,1 & 0,0 & 0,0 & 0,2 & 0,0 & 0,0 & 0,0 & 0,5 \\
\hline & VTcc & 0,0 & 0,6 & 0,6 & 0,1 & 0,1 & 0,5 & 0,0 & 0,0 & 1,7 & 0,0 & 0,0 & 0,0 & 3,6 \\
\hline & VFec & 0,0 & 0,5 & 0,6 & 0,1 & 0,2 & 0,5 & 0,0 & 0,0 & 1,5 & 0,0 & 0,0 & 0,0 & 3,5 \\
\hline \multirow{4}{*}{ Total } & DA & 525,6 & 135,6 & 124,4 & 92,2 & 74,4 & 48,9 & 30,0 & 32,2 & 16,7 & 2,2 & 4,4 & 2,2 & 1088,9 \\
\hline & DoA & 0,0 & 0,6 & 1,5 & 2,3 & 2,9 & 2,9 & 2,5 & 3,4 & 2,4 & 0,4 & 0,9 & 0,6 & 20,3 \\
\hline & VTcc & 0,0 & 2,7 & 8,3 & 15,8 & 25,0 & 27,3 & 25,9 & 35,2 & 26,9 & 2,9 & 9,8 & 8,4 & 188,2 \\
\hline & VFcc & 0,0 & 2,4 & 7,7 & 14,1 & 22,6 & 25,4 & 22,4 & 29,3 & 22,1 & 3,2 & 7,5 & 7,6 & 164,3 \\
\hline
\end{tabular}

O elevado número de indivíduos na menor classe de diâmetro indica que a maioria das populações das espécies regenerantes no sub-bosque está em fase inicial de estabelecimento (BRITO et al., 2006). A maior concentração de indivíduos nas primeiras classes de diâmetro pode caracterizar uma comunidade estoque, o que é padrão em florestas tropicais estáveis com idade e composição de espécies variadas (SCOLFORO, 1998).

A densidade total (DTA), dominância total (DoT) e os volumes total (VTcc) e de fuste com casca (VFcc) alcançaram 1.089 fustes.ha ${ }^{-1}, 20,339 \mathrm{~m}^{2} \cdot \mathrm{ha}^{-1}, 188,228 \mathrm{~m}^{3} \cdot \mathrm{ha}^{-1}$ e $164,259 \mathrm{~m}^{3} \cdot \mathrm{ha}^{-1}$, respectivamente (Tabela 4). A população de Anadenanthera peregrina totalizou 642 fustes.ha ${ }^{-1}$, dominância absoluta de $19,792 \mathrm{~m}^{2} \cdot \mathrm{ha}^{-1}(97 \%)$ e VTcc e VFcc de $184,624 \mathrm{~m}^{3} \cdot \mathrm{ha}^{-1}(98 \%)$ e $160,760 \mathrm{~m}^{3} \cdot \mathrm{ha}^{-1}(98 \%)$. Os altos valores de dominância e volumes total e de tronco com casca o que confere ao povoamento elevado potencial para produção de madeira, estocagem e sequestro de carbono e, em geral, para recuperação de áreas degradadas, principalmente de áreas de reserva legal.

\section{CONCLUSÕES}

Os resultados deste trabalho confirmam a hipótese de que a dominância forte de Anadenanthera peregrina aliada a efeitos alelopáticos inibiu a regeneração natural de espécies arbustivo-arbóreas autóctones no plantio monoespecífico. As principais espécies que cohabitam o plantio de Anadenanthera peregrina foram Platypodium elegans, Sparattosperma leucanthum, Brosimum guianense e Diatenopteryx sorbifolia. Contudo, decorridos mais de 30 anos do plantio de A. peregrina, a distribuição dos diâmetros, incluindo a regeneração natural, apresenta a tendência de J-invertido, que é típica de florestas nativas inequiâneas.

\section{REFERÊNCIAS}

ARAÚJO, F. S.; MARTINS, S. V.; MEIRA NETO, J. A. A.; LANI, J. L.; PIRES, I. E. Florística da vegetação arbustivoarbórea colonizadora de uma área degradada por mineração de caulim, em Brás Pires, MG. Revista Árvore, Viçosa, MG, v. 29, n. 6, p. 107-116, nov./dez. 2005.

BRASIL. Lei n. 4771, de 15 de setembro de 1965. Institui o novo código florestal. Brasília, 1965. Disponível em: $<\mathrm{http} / /$ www.planalto.gov.br/ccivil_03/Leis/L4771.htm>. Acesso em: 10 jul. 2010.

BRITO, E. R.; MARTINS, S. V.; OLIVEIRA FILHO, A. T.; SILVA, E.; SILVA, A. F. Estrutura fitossociológica de um fragmento natural de floresta inundável em área de orizicultura irrigada, município de Lagoa da Confusão, Tocantins. Revista Árvore, Viçosa, MG, v. 30, p. 829-839, 2006.

Cerne, Lavras, v. 18, n. 3, p. 413-421, jul./set. 2012 
CAMPELLO, E. F. C. Sucessão vegetal na recuperação de áreas degradadas. In: DIAS, L. E.; MELLO, L. W. V. (Ed.). Recuperação de áreas degradadas. Viçosa, MG: UFV/ SOBRADE, 1998. p. 183-196.

CARVALHO, P. E. R. Espécies arbóreas brasileiras. Brasília: EMBRAPA Informação Tecnológica; Colombo: EMBRAPA Florestas, 2003. 1039 p.

CETEC. Determinação de equações volumétricas aplicáveis ao manejo sustentado de florestas nativas do estado de Minas Gerais e outras regiões do país: relatório final. Belo Horizonte: FAPEMIG/CETEC, 1995. 295 p.

CONSULTORIA E DESENVOLVIMENTO DE SISTEMAS. Mata nativa 2: manual do usuário. Viçosa, MG, 2006. 295 p.

DURIGAN, G.; FRANCO, G. A. D. C.; PASTORE, J. A.; AGUIAR, O. T. Regeneração natural da vegetação de Cerrado sob floresta de Eucalyptus citrodora. Revista do Instituto Florestal, Piracicaba, v. 9, n. 1, p. 71-85, 1997.

GELDENHUYS, C. J. Native forest regeneration in pine and eucalypt plantations in Northern Province, South África. Forest Ecology and Management, Amsterdam, v. 99, p. 101$115,1997$.

GOLFARI, L. Zoneamento ecológico do Estado de Minas Gerais para reflorestamento. Brasília: $\mathrm{PNUD/FAO/IBDF/}$ BRA, 1975. 65 p. (Série Técnica, 45).

HARPER, J. L. Population biology of plants. London: Academic, 1977. 891 p.

LOETSCH, F.; HALLER, K. E.; ZORHER, F. Forest inventory. $2^{\text {nd }}$ ed. Munich: BLV Verlagsgesellschaft, 1973. v. 2, $469 \mathrm{p}$.

LOPES, W. P.; SILVA, A. F.; SOUZA, A. L. de; MEIRA NETO, J. A. A. Estrutura fitossociológica de um trecho de vegetação arbórea no Parque Estadual do Rio Doce, Minas Gerais, Brasil. Acta Botânica Brasílica, Porto Alegre, v. 16, n. 4, p. 443-456, 2002.

LOUMETO, J. J.; HUTTEL, C. Understory vegetation in fast-growing tree plantations on savanna soils in Congo. Forest Ecology and Management, Amsterdam, v. 99, p. 65-81, 1997.

Cerne, Lavras, v. 18, n. 3, p. 413-421, jul./set. 2012
MEIRA NETO, J. A. A.; MARTINS, F. R. Estrutura do sub-bosque herbáceo-arbustivo da Mata da Silvicultura, uma Floresta Estacional Semidecidual no Município de Viçosa, MG. Revista Árvore, Viçosa, v. 27, n. 4, p. 459-471, jul./ago. 2003.

MENDONÇA, R. C.; FELFILI, J. M.; WALTER, B. M. T.; SILVA-JUNIOR, M. C.; REZENDE, A. V.; FILGUEIRA, T. S.; NOGUEIRA, P. E. Flora vascular do Cerrado. In: SANO, S. M.; ALMEIDA, S. P. (Ed.). Cerrado: ambiente e flora. Planaltina: EMBRAPA Cerrados, 1998. p. 289-556.

MIKICH, S. B.; SILVA, S. M. Composição florística e fenologia das espécies zoocóricas de remanescentes de Floresta Estacional Semidecidual no Centro-Oeste do Paraná, Brasil. Acta

Botânica Brasílica, Porto Alegre, v. 15, n. 1, p. 89-113, 2001.

MINAS GERAIS. Lei $\mathbf{n}^{\circ} \mathbf{1 7 . 2 2 7}$, de 13 de agosto de 2008. Dispõe sobre a concessão de incentivo financeiro a proprietários e posseiros rurais, sob a denominação de Bolsa Verde, para os fins que especifica, e altera as Leis nºs 13.199 , de 29 de janeiro de 1999, que dispõe sobre Política Estadual de Recursos Hídricos, e 14.309, de 19 de junho de 2002, que dispõe sobre as políticas florestais e de proteção da biodiversidade no Estado. Belo Horizonte, 2008. Disponível em: $<$ http://www.siam.mg.gov.br/sla/download. pdf?idNorma=8952>. Acesso em: 13 jul. 2010.

MUELLER-DOMBOIS, D.; ELLENBERG, H. Aims and methods of vegetation ecology. New York: Willey, 1974. 547 p.

NAPPO, M. E.; OLIVEIRA FILHO, A. T.; MARTINS, S. V. A estrutura do sub-bosque de povoamentos homogêneos de Mimosa scabrella Bentham, em área minerada, em Poços de Caldas, MG. Ciência Florestal, Santa Maria, v. 10, n. 2, p. 17-29, 2000.

NASCIMENTO, G.; PIFANO, D. S.; LIMA, M.; CALEGARIO, N. Floristic aspects and diversity of regenerated arboreal species under a stand of Anadenanthera peregrina Speg. Cerne, Lavras, v. 15, p. 187-195, 2009.

NERI, A. V.; CAMPOS, E. P.; DUARTE, T. G.; MEIRA NETO, J. A. A.; SILVA, A. F.; VALENTE, G. E. Regeneração de espécies nativas lenhosas sob plantio de Eucalyptus em área de Cerrado na Floresta Nacional de Paraopeba, MG, Brasil. Acta Botânica Brasílica, Porto Alegre, v. 19, n. 2, p. 369-376, 2005. 
ODUM, E. P. Ecologia. Rio de Janeiro: Guanabara, 1983. $434 \mathrm{p}$.

OLIVEIRA FILHO, A. T.; FONTES, M. A. Patterns of floristic differentiation among Atlantic Forest in Southeastern Brazil and the influence of climate. Biotropica, Oxford, v. 32, n. 4B, p.793-810, 2000.

PAULA, A. P.; SILVA, A. F.; MARCO JÚNIOR, P. de; MAËS DOS SANTOS, F. A.; SOUZA, A. L. Sucessão ecológica da vegetação arbórea em uma Floresta Estacional Semidecidual, Viçosa, MG, Brasil. Acta Botânica Brasílica, Porto Alegre, v. 18, n. 3, p. 407-423, 2004.

PIELOU, E. C. Ecological diversity. New York: J. Wiley, 1975. $165 \mathrm{p}$.

RIBAS, R. F.; MEIRA NETO, J. A. A.; SILVA, A. F. da; SOUZA, A. L. de. Composição florística de dois trechos em diferentes etapas serais de uma Floresta Estacional Semidecidual em Viçosa, Minas Gerais. Revista Árvore, Viçosa, v. 27, n. 6, p. 821-830, nov./dez. 2003.

RODRIGUES, R. R.; MARTINS, S. V.; BARROS, L. C. Tropical rain forest regeneration in an area degraded by mining in Mato Grosso State, Brazil. Forest Ecology and Management, Amsterdam, v. 90, p. 323-333, 2004.

SARTORI, M. S.; POGGIANI, F.; ENGEL, V. L. Regeneração da vegetação arbórea nativa no subbosque de um povoamento de Eucalyptus saligma Smith. localizado no Estado de São Paulo. Scientia Forestalis, Piracicaba, n. 62, p. 86-103, 2002.

SCOLFORO, J. R. S. Manejo florestal. Lavras: UFLA/ FAEPE, 1998. 438 p.

SILVA, V. F.; VENTURIN, N.; OLIVEIRA-FILHO, A. T.; MACEDO, R. L. G.; CARVALHO, W. A. C.; BERG, E. van den. Caracterização estrutural de um fragmento de floresta semidecídua no município de Ibituruna, MG. Cerne, Lavras, v. 9, n. 1, p. 92-106, 2003.

SILVA JÚNIOR, W. M.; MARTINS, S. V.; SILVA, A. F.; MARCO JUNIOR, P. Regeneração de espécies arbustivoarbórea em dois trechos de uma Floresta Estacional
Semidecidual, Viçosa, MG. Scientia Forestalis, Piracicaba, v. 66, p. 169-179, 2004.

SOARES, C. P. B.; SOUZA, A. L.; AMARO, M. A.; COELHO, D. J.; GASPAR, R. O. Equações volumétricas, hipsométricas e de taper para angico vermelho (Anadenanthera peregrina Speg.). Revista Árvore, Viçosa, v. 34, p. 431-437, 2010.

SOUZA, P. B.; MARTINS, S. V.; COSTALONGA, S. R.; COSTA, G. O. Florística e estrutura da vegetação arbustivoarbórea no sub-bosque de povoamento de Eucalyptus grandis W. Hill ex Maiden, em Viçosa, MG, Brasil. Revista Árvore, Viçosa, v. 31, p. 533-543, 2007.

SOUZA, P. B.; MEIRA NETO, J. A. A.; SILVA, A. F.; SOUZA, A. L. Composição florística da vegetação arbórea de um remanescente de cerradão, Paraopeba, MG. Revista Árvore, Viçosa, v. 32, p. 771-780, 2008.

SOUZA, V. C.; LORENZI, H. Botânica sistemática: guia ilustrado para identificação das famílias de Angiospermas da flora brasileira, baseado em APG II. Nova Odessa: Instituto Plantarum, 2005.

VELOSO, H. P.; RANGEL FILHO, A. L. R.; LIMA, J. C. A. Classificação da vegetação brasileira adaptada a um sistema universal. São Paulo: Fundação Instituto Brasileiro de Geografia e Estatística, 1991. 123 p.

VILAR, M. B.; JACOVINE, L. A. G.; SOUZA, A. L. Pagamento por serviços ambientais: alternativa para a efetivação da proteção ambiental em propriedades rurais.

Informe Agropecuário, Belo Horizonte, v. 30, n. 252, p. 1623, 2009.

WERNECK, M. S.; PEDRALLI, G.; KOENIG, R.; GIESEKE, L. F. Florística e estrutura de três trechos de uma floresta semidecídua na Estação Ecológica do Tripuí, Ouro Preto, MG. Revista Brasileira de Botânica, São Paulo, v. 23, p. 97-106, 2000.

WISCH, E. N.; MELO, A. C. G. Análise do crescimento de cinco espécies nativas do Cerrado no oeste do Estado de São Paulo. Revista Científica Eletrônica de Engenharia Florestal, Garça, v. 5, p. 1-8, 2005.

Cerne, Lavras, v. 18, n. 3, p. 413-421, jul./set. 2012 
